Original article

\title{
Overweight/obesity risks and prevalence of diabetes and hypertension in North Eastern India: An analysis using seemingly unrelated probit model
}

\author{
Strong P. Marbaniang ${ }^{a, *}$, Hemkhothang Lhungdim ${ }^{a}$, Brijesh Yadav ${ }^{b}$, Vinit Kumar Yajurvedi ${ }^{\mathrm{c}}$ \\ ${ }^{a}$ Department of Public Health and Mortality Studies, International Institute for Population Sciences, Mumbai, Maharashtra-400088, India \\ ${ }^{\mathrm{b}}$ District Specialist Monitoring and Evaluation, Indian Health Action Trust, Lucknow, India \\ ${ }^{\mathrm{c}}$ Research Analyst, Cvoter News Service Pvt Lt, Noida NCR, India
}

\section{A R T I C L E I N F O}

\section{Keywords:}

Overweight/obesity

Diabetes

Hypertension

Seemingly unrelated probit model

North eastern India

\begin{abstract}
A B S T R A C T
Objective: It would be reasonable to hypothesize that common unobserved factors, such as psychological stress and anxiety, as well as genetic and environmental factors, simultaneously influence the tendency for overweight or obesity and the prevalence of chronic disease. The paper tries to examine the joint influence of an individual's and socio-economic characteristics in determining overweight or obesity and chronic disease.

Methods: The sample comprised of 112,062 male and female participants age 15-49 years. For the simultaneous joint estimation approach we employ a seemingly unrelated probit model with and without control for endogeneity.

Results: The non-zero correlation coefficient obtained from the analysis reveals that overweight or obesity is related to diabetes and hypertensions, indicating the existence of unmeasurable individual factors that commonly affect the propensity to diabetes and hypertension and overweight or obesity. A $10 \%$ increase in overweight and obesity causes increment of $4 \%$ in diabetes, $4.9 \%$ in hypertension. Further, among the overweight or obese individual, a $10 \%$ increase in overweight and obesity causes increment of $4.7 \%$ in diabetes, and $6.5 \%$ in hypertension in the study area.

Conclusion: The study indicates presence of unobserved factors that simultaneously affect overweight/obesity and prevalence of both diabetes and hypertension. Policy and health promotion programme should also give special attention to the unmeasurable factors (for example: genetic factors, psychological stress and long working hour) that commonly influence the risk of overweight or obesity and chronic diseases.
\end{abstract}

\section{Introduction}

Northeast India reported a high proportion of overweight or obesity across the region. The National Family Health Survey in 2005-06 (NFHS-3) reported that the prevalence of overweight or obesity in the region varies from 5.3 to $15.4 \%$ among women and from 4.8 to $11.9 \%$ among men, with the state of Manipur, Sikkim, Meghalaya and Nagaland reporting a prevalence which is above the national level. ${ }^{1}$ The increased risk of hypertension and diabetes due to overweight and obesity have also been reported from studies in Northeast India. A study conducted in Manipur showed that those who are overweight or obese were 7.39 times more likely to have stage II hypertension. ${ }^{2}$ A cross-sectional study of out-patients and in-patients of hospitals in urban Assam found that the prevalence of T2 diabetes among overweight and obese were, respectively, $15.5 \%$ and $20.2 \%{ }^{3}$ The studies cited were based on micro-level data obtained from different pockets of the region, or referred to specific population groups because of which the results may not be representative of the entire population of Northeast India. In spite of overwhelming evidence of a clear association between overweight or obesity and the presence of chronic diseases, the joint effects of overweight or obesity - together with the other explanatory variables on the incidence of chronic diseases is still poorly understood. In economic terms, overweight or obesity can be considered as a potential risk factor that are influenced by other risk factors, such as lifestyle, rather than a single negative input for poor health outcomes. ${ }^{4}$ It would be reasonable to hypothesize that common unobserved factors, such as psychological stress and anxiety, as well as genetic and environmental factors, simultaneously influence the tendency for overweight or obesity and the prevalence of chronic disease. ${ }^{4,5}$

Overweight or obesity in an individual is likely to correlate with the

\footnotetext{
* Corresponding author.

E-mail address: marbaniangstrong@gmail.com (S.P. Marbaniang).
} 
unobserved determinants of chronic disease condition. ${ }^{6}$ Even though obesity arises from complex social and biological phenomena, it is often viewed as the outcome of an individual's behaviors. Yamada et al. (2002), in their study, hypothesized three ways that might facilitate weight gain: (1) job stress which could lead to unhealthy behavior like heavy smoking, high alcohol consumption, and sedentary leisure activities, all of which are associated with weight gain; (2) psychological strain which could lead to changes in the body's endocrine activity which is associated with weight gain; and (3) long working hours, overtime and shift work that could lead to exhaustion and hinder behavior that prevents weight gain and accumulation of abdominal fat. ${ }^{7}$ The pioneering contribution of this study is its attempt to address the issue from the perspective of the potential influence of endogeneity arising from the unobserved factors on overweight or obesity, as well as the incidence of diabetes or hypertension. Roberts and Whited, (2013) define endogeneity as a correlation between the explanatory variables and the error term in a regression. ${ }^{8}$ Endogeneity may arise due to the omission of explanatory variables in the regression, which would results in the error term being correlated with the explanatory variables. ${ }^{9}$

The present study investigates the effect of overweight or obesity on diabetes and hypertension using the 2015-16 Indian Demographic Health Survey data. Unlike previous studies ${ }^{2,3}$ we propose a simultaneous joint estimation approach which deals with endogeneity and unobserved heterogeneity. We propose a seemingly unrelated probit model with and without controls for endogeneity to understand the joint influence of an individual's and socio-economic characteristics in determining overweight or obesity and chronic disease. This model offers significant advantages over other models because it allows the detection of correlations between the error terms of two equations and controls for potential reverse causality problems. ${ }^{10}$ Thus, the combined determinants of overweight or obesity and chronic diseases can be examined and the findings may help in the planning of health promotion policies in an 'obesogenic environment.'

\section{Material and methods}

The study used data of the fourth round of the National Family Health Survey (NFHS-4). Since this study is based on analysis of secondary data which is publicly available, and the respondents are deidentified, the institutional review board (IRB) exempted this study from requiring its approval. The survey followed a stratified two-stage sampling design. From each selected household, information was sought from the women age 15-49 years and men aged 15-54 years. The procedure followed to select respondents from the sample households has been designed to be representative at national and state levels. ${ }^{11}$

\subsection{Study sample for North-east India region}

The study sample comprised of 112, 062 respondents (both females and males) from Northeast India age15-49. Out of the total sample 13,360 were males and 98,702 were female respondents. Male respondents consist only $12 \%$ of the total sample since the survey collected information about male from only $15 \%$ of the total sample households. Further, 6878 respondents had diabetes, 17,677 respondents had hypertension, and 36,712 respondents were overweight or obese.

\subsection{Operational definitions}

Diabetes: Finger stick blood is collected and blood glucose level is determined using the Free Style Optium H Glucometer. Usually, fasting blood glucose level is used to determine the presence or absence of diabetes in an individual. However, NFHS- 4 collected the random blood glucose, with specified standard cut-off values. For instance, a respondent is considered to have diabetes if the random blood sugar level is $>$ $140 \mathrm{mg} / \mathrm{dl}^{11}$

Hypertension: Blood pressure was measured using OMRON Blood
Pressure monitor. Blood pressure readings were taken on three separate occasions with an interval of $5 \mathrm{~min}$ between readings. The first reading will be discarded and the average of the last two readings will be calculated. A respondent is classified as hypertensive if the average systolic blood pressure $\geq 140 \mathrm{mmHg}$, or average diastolic blood pressure $\geq 90 \mathrm{mmHg}$, or if the person was taking antihypertensive medication to lower blood pressure at the time of the survey. ${ }^{11}$

Overweight and Obesity: The study categorizes continuous body mass index (BMI) according to the WHO guidelines. A respondent is classified as overweight if BMI is in the range $23-27.5 \mathrm{~kg} / \mathrm{m}^{2}$ and obese if $\mathrm{BMI} \geq 27.5 \mathrm{~kg} / \mathrm{m}^{2} .^{12}$

\subsection{Dependent variables}

The outcome variables in this study are diabetes, hypertension, and overweight or obesity status of the respondent. The outcomes variables are binary with a value of 1 for a "Yes" (meaning presence) and 0 for a "No" (meaning absence). The definitions and types of variables are provided in Table A1.

\subsection{Explanatory variables}

The explanatory variables chosen for this study were guided by existing literature. Demographic variables considered are age and sex. Socio economic variables include respondent's caste, marital status, level of education, place of residence and household wealth. The variable lifestyle behavior includes current cigarettes smoking and alcohol consumption. To capture the effect of dietary eating habits on chronic diseases, we include the types of food consumed by an individual, such as consumption of milk, fish, fruits, aerated drinks and fried food. Table A1 provides information on the types of variables used in the study.

\subsection{Seemingly unrelated probit model}

This study applied the seemingly unrelated bivariate probit model to determine the explanatory factors of diabetes or hypertension. The seemingly unrelated bivariate probit model is applied when two equations are to be estimated, and the dependent variable of one of them becomes the independent variable in the other equation. ${ }^{13}$ This model has the advantage of allowing testing to determine if the correlation between the two-error terms is non-null. A significant non-null correlation would indicate the existence of unmeasurable variables that are common to the risk of being overweight or obese and having diabetes or hypertension.

Suppose that overweight or obesity is identified by the latent variable $\mathrm{O}_{1 \mathrm{i}}^{*}$ and that $\mathrm{C}_{2 \mathrm{i}}^{*}$ is the latent variable determining the presence of chronic disease (diabetes or hypertension). Then, the unobserved variables can be modeled as follows,

$\mathrm{O}_{1 \mathrm{i}}^{*}=\beta_{1} \mathrm{X}_{1 \mathrm{i}}+\mu_{1 \mathrm{i}}$

Where. $\mathrm{O}_{1 \mathrm{i}}=\left\{\begin{array}{l}1, \text { if } \mathrm{O}_{1 \mathrm{i}}^{*}>0 \\ 0, \text { Otherwise }\end{array}\right.$

Where $i=1,2 \ldots, n$, represents the ith individual, $X_{1 i}$ refers to the observed determinants of overweight or obesity, $\beta_{1 \mathrm{i}}$ are the associated parameters, and $\mu_{1 \mathrm{i}}$ is a random error term. Similarly, the risk of suffering from chronic disease is measured with the help of the equation,

$C_{2 \mathrm{i}}^{*}=\beta_{2} \mathrm{X}_{2 \mathrm{i}}+\mu_{2 \mathrm{i}}$

Where $\mathrm{C}_{2 \mathrm{i}}=\left\{\begin{array}{l}1, \text { if } \mathrm{C}_{2 \mathrm{i}}^{*}>0 \\ 0, \text { Otherwise }\end{array}\right.$

Where $\mathrm{X}_{2 \mathrm{i}}$ refers to the observed determinants of chronic disease, $\beta_{2 \mathrm{i}}$ the associated parameters and $\mu_{2 \mathrm{i}}$ is a random error term. The error terms of the two models are dependent and distributed as a bivariate 
Table 1

Prevalence of Diabetes, Hypertension and Overweight or obesity among adults age 15-49 years by selected background characteristics, India, 2015-16.

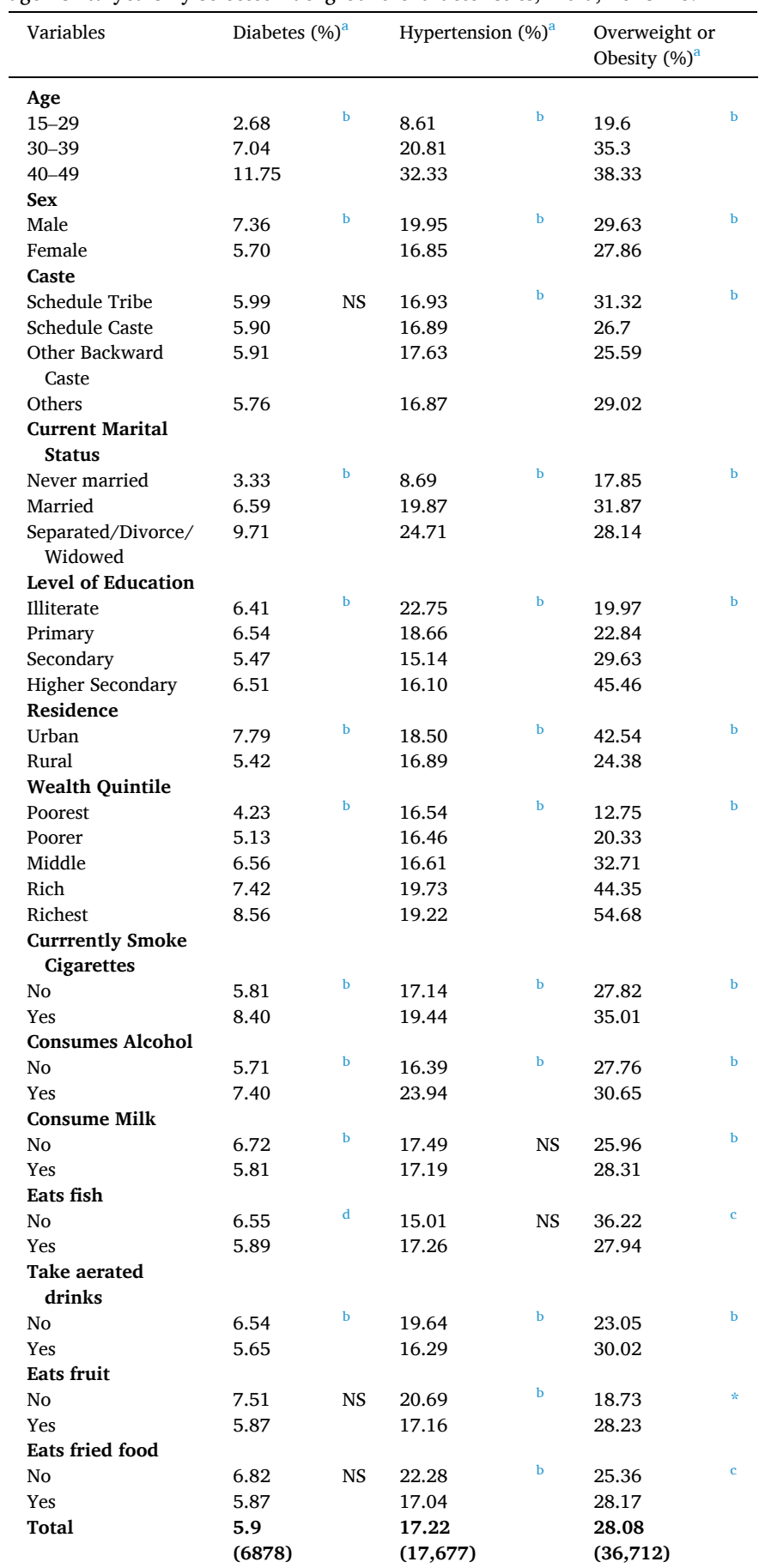

a Test of difference for categorical variables with Pearson's Chi-Square test.

b P-value $<0.01$.

c P-value $<0.05$.

d P-value $<0.1$, NS:Not Significant.

normal such that $\mathrm{E}\left(\mu_{1 \mathrm{i}}\right)=\mathrm{E}\left(\mu_{2 \mathrm{i}}\right)=0$, var $\left(\mu_{1 \mathrm{i}}\right)=\operatorname{var}\left(\mu_{2 \mathrm{i}}\right)=1$, and $\rho=$ $\operatorname{cov}\left(\mu_{1 \mathrm{i}} \mu_{2 \mathrm{i}}\right)$. A Wald test for $\rho=0$ indicates whether the models should be estimated jointly.
2.6. Seemingly unrelated probit model with overweight or obesity as the covariate variable

In this model the dependent variable $\mathrm{O}_{1 \mathrm{i}}^{*}$ of the first equation (1) becomes the risk factor for the second equation (2). The equation representing the model is as follows.

$\mathrm{O}_{1 \mathrm{i}}^{*}=\beta_{1} \mathrm{X}_{1 \mathrm{i}}+\mathrm{\epsilon}_{1 \mathrm{i}}$

$\mathrm{C}_{2 \mathrm{i}}^{*}=\delta_{1} \mathrm{O}_{1 \mathrm{i}}+\delta_{2} \mathrm{Z}_{2 \mathrm{i}}+\mathrm{\epsilon}_{2 \mathrm{i}}$

Where $\mathrm{O}_{1 \mathrm{i}}^{*}$ andC $\mathrm{C}_{2 \mathrm{i}}^{*}$ are latent dummy variables as in (1) and (2), $\mathrm{X}_{1 \mathrm{i}}$ determinants of overweight or obesity, $\mathrm{Z}_{2 \mathrm{i}}$ determinants of chronic disease and $\beta_{1} \delta_{1}, \delta_{2}$ are parameters of the behavioral function. The error terms of the two models are dependent and distributed as a bivariate normal such that $\mathrm{E}\left(\varepsilon_{1 \mathrm{i}}\right)=\mathrm{E}\left(\varepsilon_{2 \mathrm{i}}\right)=0$, $\operatorname{var}\left(\varepsilon_{1 \mathrm{i}}\right)=\operatorname{var}\left(\varepsilon_{2 \mathrm{i}}\right)=1$, and $\rho=\operatorname{cov}\left(\varepsilon_{1 \mathrm{i}} \varepsilon_{2 \mathrm{i}}\right)$ (4). The Wald test and a Lagrange multiplier test, provide an indication of the correlation between the unobserved explanatory variables of both equations so that if $\rho=0$ then $\mathrm{O}_{1 \mathrm{i}}$ is a risk factor not influence by unobserved factors in the second equation. ${ }^{14}$

\section{Results}

\subsection{Study variables descriptive statistics}

Descriptive statistics of the variables are presented in Table A2. Our estimates are based on data obtained from respondents age 15-49 years. The mean blood glucose level of the sample was $106.42 \mathrm{mg} / \mathrm{dl}$ with a minimum and maximum value of $70 \mathrm{mg} / \mathrm{dl}$ and $499 \mathrm{mg} / \mathrm{dl}$ respectively. Mean average systolic and diastolic blood pressures were $118.82 \mathrm{mmHg}$ and $79.58 \mathrm{mmHg}$ respectively.

Fig. 1 illustrates the BMI distribution by the status of Diabetes and Hypertension. The solid line represents BMI distribution for the population with diabetes and hypertension while dash line represents it for the population with no diabetes and hypertension. It is evident that the BMI distribution of the diabetic and hypertensive population lies to the right of the BMI distribution of the non diabetic and non hypertensive population. This indicates that the diabetic and hypertensive population are more likely to report higher BMI level. While respectively $47 \%$ and $44 \%$ of the diabetic and hypertensive population has BMI greater than 23 , this proportion is only $27 \%$ and $25 \%$ amongst the non diabetic and hypertensive.

Prevalence of Diabetes, Hypertension and Overweight or obesity among adults is presented in Table 1 . The study reveals that the prevalence of diabetes and hypertension among adults age 15-49 years in North-east India is $5.9 \%$ and $17.2 \%$ respectively. Further, a high prevalence $(28 \%)$ of overweight or obesity among adults was observed in the study region. As the age of respondent increases, the prevalence of diabetes, hypertension and overweight or obesity also significantly increases. Furthermore, cigarettes smoking and alcohol consumption found significantly related with the prevalence of chronic diseases. The prevalence of diabetes is $8.4 \%$ among cigarette smokers and $5.8 \%$ among non-smokers. Similarly, the prevalence of hypertension was $23.9 \%$ among alcohol drinkers and $16.4 \%$ among the non-drinkers.

\subsection{Effect of overweight/obesity on chronic diseases: results from seemingly unrelated probit model}

The results of the estimated coefficients are presented in Tables 2 and 3 and Table 4. In Table 2 the results presents the coefficients for overweight or obese, diabetes and hypertension using single probit model. Comparing the estimated coefficients with those in Table 3, Table 4, and Table A3, obtained using the seemingly unrelated bivariate probit model, reveals small difference in terms of values and statistical significance. Further, in the seemingly unrelated biprobit model, the rho $(\rho)$ association indicates the correlation between the residuals term in the 
Table 2

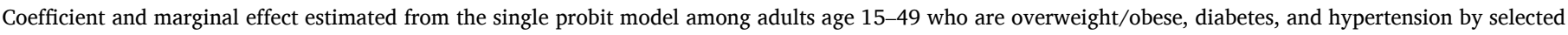
characteristics, India, 2014-15.

\begin{tabular}{|c|c|c|c|c|c|c|}
\hline \multirow[t]{2}{*}{ Background Characteristics } & \multicolumn{2}{|c|}{ Overweight or Obese } & \multicolumn{2}{|l|}{ Diabetes } & \multicolumn{2}{|l|}{ Hypertension } \\
\hline & Coefficients & Mg.effect & Coefficients & Mg.effect & Coefficients & Mg.effect \\
\hline Age & $0.03^{\mathrm{a}}$ & $0.01^{\mathrm{a}}$ & $0.032^{\mathrm{a}}$ & $0.004^{\mathrm{a}}$ & $0.039^{\mathrm{a}}$ & $0.009^{\mathrm{a}}$ \\
\hline \multicolumn{7}{|l|}{ Sex } \\
\hline Male & Ref & & Ref & & Ref & \\
\hline Female & $-0.08^{\mathrm{a}}$ & $-0.028^{\mathrm{a}}$ & $-0.119^{\mathrm{a}}$ & $-0.014^{\mathrm{a}}$ & $-0.208^{\mathrm{a}}$ & $-0.051^{\mathrm{a}}$ \\
\hline \multicolumn{7}{|l|}{ Caste } \\
\hline Schedule Tribe & Ref & & Ref & & Ref & \\
\hline Schedule Caste & $-0.06^{\mathrm{a}}$ & $-0.020^{\mathrm{a}}$ & -0.023 & -0.002 & $0.043^{\mathrm{b}}$ & $0.010^{\mathrm{b}}$ \\
\hline Other Backward Caste & $-0.06^{\mathrm{a}}$ & $-0.023^{\mathrm{a}}$ & -0.005 & -0.001 & $0.052^{\mathrm{a}}$ & $0.012^{\mathrm{a}}$ \\
\hline Others & -0.010 & -0.004 & 0.016 & 0.002 & 0.013 & 0.003 \\
\hline \multicolumn{7}{|l|}{ Current Marital Status } \\
\hline Never married & Ref & & Ref & & Ref & \\
\hline Married & $0.34^{\mathrm{a}}$ & $0.118^{\mathrm{a}}$ & $-0.073^{\mathrm{a}}$ & $-0.008^{\mathrm{a}}$ & $0.048^{\mathrm{a}}$ & $0.011^{\mathrm{a}}$ \\
\hline Widowed/Divorced/Separated & $0.18^{\mathrm{a}}$ & $0.058^{\mathrm{a}}$ & -0.035 & -0.004 & 0.027 & 0.006 \\
\hline \multicolumn{7}{|l|}{ Level of education } \\
\hline Illiterate & Ref & & Ref & & Ref & \\
\hline Primary & $0.02^{\mathrm{b}}$ & 0.006 & $0.058^{\mathrm{b}}$ & $0.06^{\mathrm{b}}$ & $-0.075^{\mathrm{a}}$ & $-0.017^{\mathrm{a}}$ \\
\hline Secondary & 0.120 & $0.043^{\mathrm{a}}$ & 0.032 & $0.004^{\mathrm{c}}$ & $-0.065^{\mathrm{a}}$ & $-0.015^{\mathrm{a}}$ \\
\hline Higher Secondary & 0.240 & $0.088^{\mathrm{a}}$ & 0.029 & 0.003 & $-0.091^{\mathrm{a}}$ & $-0.021^{\mathrm{a}}$ \\
\hline \multicolumn{7}{|l|}{ Residence } \\
\hline Urban & Ref & & Ref & & Ref & \\
\hline Rural & $-0.07^{\mathrm{a}}$ & $-0.026^{\mathrm{a}}$ & $-0.074^{\mathrm{a}}$ & $-0.008^{\mathrm{a}}$ & $-0.018^{\mathrm{a}}$ & -0.004 \\
\hline \multicolumn{7}{|l|}{ Wealth Index } \\
\hline Poorest & Ref & & Ref & & Ref & \\
\hline Poorer & $0.23^{\mathrm{a}}$ & $0.067^{\mathrm{a}}$ & $0.068^{\mathrm{a}}$ & $0.007^{\mathrm{a}}$ & $0.055^{\mathrm{a}}$ & $0.012^{\mathrm{a}}$ \\
\hline Middle & $0.5^{\mathrm{a}}$ & $0.160^{\mathrm{a}}$ & $0.108^{\mathrm{a}}$ & $0.011^{\mathrm{a}}$ & $0.065^{\mathrm{a}}$ & $0.014^{\mathrm{a}}$ \\
\hline Richer & $0.70^{\mathrm{a}}$ & $0.236^{\mathrm{a}}$ & $0.169^{\mathrm{a}}$ & $0.018^{\mathrm{a}}$ & $0.125^{\mathrm{a}}$ & $0.028^{\mathrm{a}}$ \\
\hline Richest & $0.82^{\mathrm{a}}$ & $0.285^{\mathrm{a}}$ & $0.210^{\mathrm{a}}$ & $0.024^{\mathrm{a}}$ & $0.098^{\mathrm{a}}$ & $0.022^{\mathrm{a}}$ \\
\hline \multicolumn{7}{|l|}{ Currently Smoke Cigarrettes } \\
\hline No & Ref & & Ref & & Ref & \\
\hline Yes & $-0.10^{\mathrm{a}}$ & $-0.035^{\mathrm{a}}$ & 0.024 & 0.003 & $-0.165^{\mathrm{a}}$ & $-0.034^{\mathrm{a}}$ \\
\hline \multicolumn{7}{|l|}{ Consume alcohol } \\
\hline No & & & Ref & & Ref & \\
\hline Yes & & & 0.003 & 0.0003 & $0.179^{\mathrm{a}}$ & $0.043^{\mathrm{a}}$ \\
\hline \multicolumn{7}{|l|}{ Consume milk } \\
\hline No & Ref & & Ref & & Ref & \\
\hline Yes & -0.010 & -0.005 & $-0.037^{b}$ & $-0.004^{\mathrm{b}}$ & 0.026 & 0.006 \\
\hline \multicolumn{7}{|l|}{ Eats fish } \\
\hline No & & & Ref & & Ref & \\
\hline Yes & & & -0.068 & -0.008 & -0.041 & -0.010 \\
\hline \multicolumn{7}{|l|}{ Takes aerated drinks } \\
\hline No & Ref & & & & & \\
\hline Yes & $0.18^{\mathrm{a}}$ & $0.06^{\mathrm{a}}$ & & & & \\
\hline \multicolumn{7}{|l|}{ Eats fruits } \\
\hline No & Ref & & Ref & & Ref & \\
\hline Yes & $-0.10^{\mathrm{a}}$ & $-0.038^{\mathrm{a}}$ & -0.046 & -0.005 & $-0.092^{\mathrm{b}}$ & $-0.022^{b}$ \\
\hline \multicolumn{7}{|l|}{ Eats friedfood } \\
\hline No & Ref & & & & & \\
\hline Yes & $-0.07^{\mathrm{a}}$ & $-0.026^{\mathrm{a}}$ & & & & \\
\hline Constant & $-1.90^{\mathrm{a}}$ & & $-2.36^{\mathrm{a}}$ & & $-2.027^{\mathrm{a}}$ & \\
\hline Log-likelihood & -58469.17 & & -22319.08 & & -40644.45 & \\
\hline Likelihood-ratio Chi & 11896.62 & & 2419.94 & & 6977.6 & \\
\hline Pseudo $\mathbf{R}^{2}$ & 0.092 & & 0.051 & & 0.0791 & \\
\hline
\end{tabular}

Ref: Reference category.

${ }^{\text {a }}$ P-value $<0.01$.

b P-value $<0.05$.

c P-value $<0.1$.

system of equation. This imply that if there is an association between the two errors in the biprobit model then the estimates of probit model gives a biased estimate of the coefficients and hence there is the need to employed biprobit model to get a correct estimate of the true association. ${ }^{15}$ In these conditions, the joint estimation procedure may improve the efficiency of the estimates. ${ }^{4}$ This supports the seemingly unrelated bivariate probit model which is the main focus of the study.

The positive correlation coefficient rho $(\rho)$ between the residuals was 0.12 for diabetes and 0.21 (Table A3) for hypertension, which was significantly different from zero at a $1 \%$ level of significance. This indicates the existence of unmeasurable factors that are common to the risk of overweight or obesity and suffering from chronic disease (diabetes or hypertension). Tables 3 and 4 shows the results of the joint estimation of the probability of an individual being overweight or obese and having diabetes and hypertension using the seemingly unrelated bivariate probit model. The table includes overweight or obese as the covariate variable in the diabetes and hypertension equation. The evidence of endogeneity for both diabetes and hypertension was supported by the Wald test (Wald $\chi^{2}=13992.07, \mathrm{p}<0.01$ and Wald $\chi^{2}=$ 20990.18, $\mathrm{p}<0.01)$ and the likelihood-ratio test $\left(\chi^{2}=8.62, \mathrm{p}<0.01\right.$ and $\chi^{2}=46.75, \mathrm{p}<0.01$ ). Here, the correlation coefficient is negative $(\rho=$ -0.25 and -0.37 ) which is different from the correlation coefficient obtained in Table A3. The average marginal effect of diabetes and hypertension shows that overweight or obese individuals have $3.5 \%$ and 


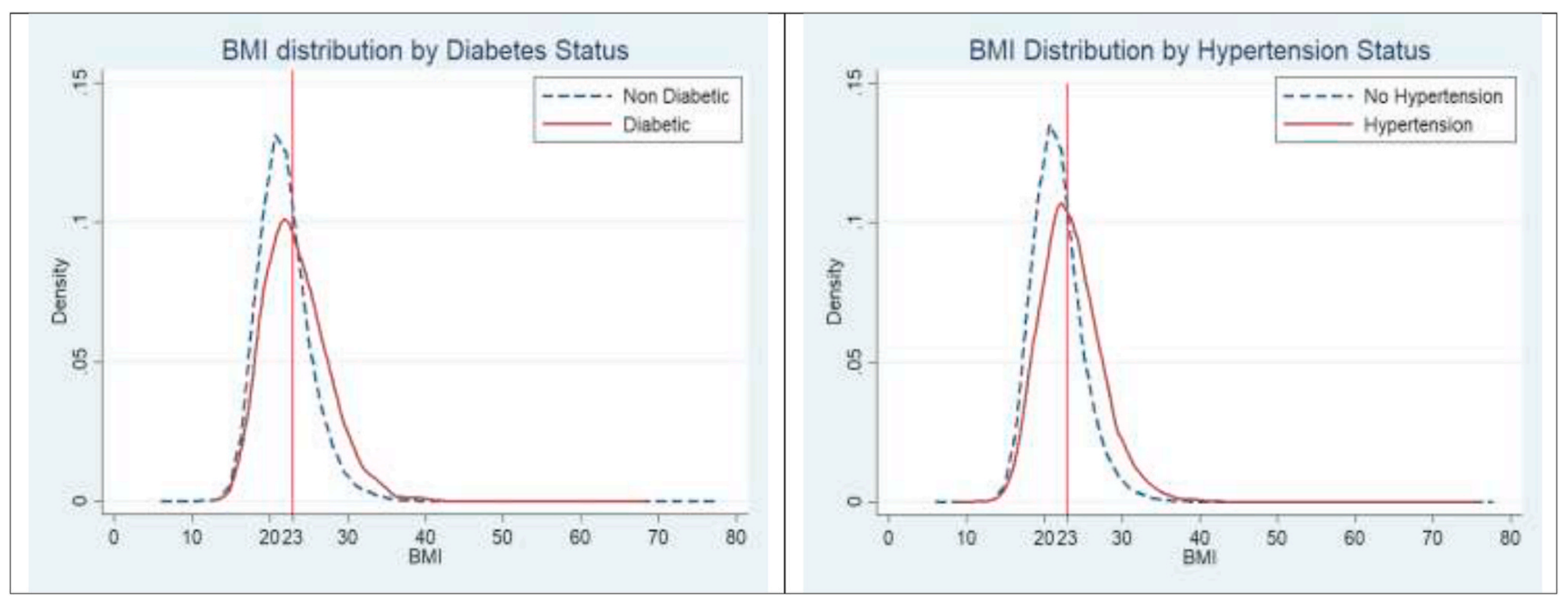

Fig. 1. BMI distribution by Status of Chronic disease. Source: Figure constructed by authors from NFHS-4 data.

$10.7 \%$ higher chances respectively of having diabetes and hypertension when compared with the chances of those who are not overweight.

In this study, age has been found to have a positive effect on the prevalence of chronic disease, and overweight or obese. The marginal effect shows that the probability of women having diabetes and hypertension, as compared to men, is significantly lower by $1.3 \%$ and $4.5 \%$. Similarly, married and widowed/divorced persons have, approximately, $12 \%$ and $6 \%$ higher chances of being overweight or obese as compared to those who are single. The household wealth index has a statistically significant relationship with the probability of a person being overweight or obese and suffering from hypertension. Respondents who currently smoke cigarettes had a low probability of becoming overweight or obese and having hypertension. Furthermore, consumption of alcohol increases the risk of a person suffering from hypertension by $4 \%$ as compared to those who did not consume.

Further, it is observed some common determinants that lower people risk to both overweight or obesity and having chronic diseases, such as being female, consumption of milk, and eating fruits. A significant and negative effect of individual level of education and wealth quintile on hypertension indicates that education and wealth influences overweight or obesity rather than directly impacting hypertension. Similarly, negative coefficients $(-0.14$ and -0.06 for diabetes; $-0.06,-0.02$ for hypertension) suggest that being married or widowed/divorced influences overweight or obesity rather than directly impacting diabetes and hypertension.

\subsection{Elasticity of overweight or obesity on the probability of having chronic disease}

The elasticity effect of overweight or obesity on chronic disease was estimated from the seemingly unrelated probit model accounting overweight or obesity as covariate variables (Tables 3 and 4). From Table 5 the elasticity of overweight and obesity evaluated at the mean indicates that a $10 \%$ increase in overweight and obesity causes increments of $4 \%$ in diabetes, and $4.9 \%$ in hypertension. Further, among the overweight and obese individuals, a $10 \%$ increase in overweight and obesity causes increment of $4.7 \%$ in diabetes, and $6.5 \%$ in hypertension.

\section{Discussion}

This paper examined the influence of overweight or obesity jointly with other determinants on the likely prevalence of diabetes and hypertension. The novel contribution of the study is that it considers the potential influence of other risk factors which are unobserved while estimating the effect of overweight or obesity on the incidence of diabetes and hypertension.

The most important finding of this study is that implicit unmeasurable variables affect an individual's propensity to have diabetes and hypertension by being overweight or obese. The non-zero correlation coefficient $(\rho)$ reveals that overweight or obesity is related to diabetes and hypertension. Possible implicit unmeasurable variables linking overweight or obesity with chronic disease may include genetic factors, psychological stress and long working hour., ${ }^{76,17}$ These variables cannot be measured, so their influences cannot be accounted for in econometric models. However, knowledge of these hidden links may help the health authorities to design more specific programmes to control overweight and chronic disease. Moreover, the positive and statistically significant correlation coefficients indicates that being overweight or obese is more likely to increase person's risk of getting diabetes and hypertension. However, the negative correlation coefficient in the model with overweight or obesity as risk factor could be due to the resulting effect of two opposing self-selection mechanisms that now appear as playing an opposite effect. This result is consistent with earlier results of application of the empirical model. ${ }^{13,14}$ Specifically, being overweight or obese is associated with an increased risk of diabetes and hypertension; but after controlling for an individual's excess weight or obesity, other unrelated effects exert an opposite effect on diabetes and hypertension. ${ }^{4}$

Results also indicate that being married increases the probability of overweight or obese as compared to persons who are not married, which is also found in earlier studies. ${ }^{18-20}$ A plausible explanation is that married persons have more family responsibilities and thus, have less time for physical exercise and may be more inclined to consume snacks and sweets with their children, leading to an increase in body weight. ${ }^{21,22}$ Among the married couple, the husband is more likely to gain weight than the wife. A change in marital status-from unmarried to married-can lead to changes in lifestyle behaviours that influence body weight. ${ }^{23}$

Another important finding relates to common factors affecting overweight or obese and chronic diseases. The common factors which do not increase the likelihood of being overweight or obese and having hypertension is currently smoking cigarettes. The existing literature is inconclusive on this issue, and some studies do not agree with such finding ${ }^{24}$; others do support the finding. ${ }^{25}$ One possible explanation is that reduction in weight can contribute to decrease blood pressure among the current smokers. ${ }^{26}$ Evidence shows that average body mass index and obesity was lower in current smokers than in non-smokers. ${ }^{26}$ Further, consumption of milk lowers the likelihood of being overweight or obese and suffers from diabetes. This is to be expected because growing evidence suggest that milk proteins are beneficial for reducing 
Table 3

Seemingly unrelated bivariate probit model with diabetes and overweight or obesity as the outcome morbidity among adults age 15-49, India, 2014-15.

\begin{tabular}{|c|c|c|c|c|}
\hline \multirow{2}{*}{$\begin{array}{l}\text { Background } \\
\text { Characteristics }\end{array}$} & \multicolumn{2}{|l|}{ Diabetes } & \multicolumn{2}{|c|}{ Overweight or Obese } \\
\hline & Coefficients & Mg.effect & Coefficients & Mg.effect \\
\hline Overweight or Obese & $0.30^{* * *}$ & $0.035^{* * *}$ & & \\
\hline Age & $0.026^{* * *}$ & $0.003^{* * *}$ & $0.03^{* * *}$ & $0.01 * * *$ \\
\hline \multicolumn{5}{|l|}{ Sex } \\
\hline Male & Ref & & Ref & \\
\hline Female & $-0.11^{* * *}$ & $-0.013^{* * *}$ & $-0.08^{* * *}$ & $-0.027^{* * *}$ \\
\hline \multicolumn{5}{|l|}{ Caste } \\
\hline Schedule Tribe & Ref & & Ref & \\
\hline Schedule Caste & -0.016 & -0.002 & $-0.05^{* * *}$ & $-0.019 * * *$ \\
\hline Other Backward Caste & 0.007 & 0.001 & $-0.06^{* * *}$ & $-0.023^{* * *}$ \\
\hline Others & 0.010 & 0.001 & -0.008 & -0.003 \\
\hline \multicolumn{5}{|l|}{$\begin{array}{l}\text { Current Marital } \\
\text { Status }\end{array}$} \\
\hline Never married & Ref & & Ref & \\
\hline Married & $-0.14 * * *$ & $-0.016^{* * *}$ & $0.34^{* * *}$ & $0.118^{* * *}$ \\
\hline $\begin{array}{l}\text { Widowed/Divorced/ } \\
\text { Separated }\end{array}$ & $-0.06^{* *}$ & -0.004 & $0.17 * * *$ & $0.057^{* * *}$ \\
\hline \multicolumn{5}{|l|}{ Level of education } \\
\hline Illiterate & Ref & & Ref & \\
\hline Primary & $0.05^{* *}$ & $0.006^{* *}$ & 0.02 & 0.008 \\
\hline Secondary & 0.003 & 0.0004 & $0.12^{* * *}$ & $0.044^{* * *}$ \\
\hline Higher Secondary & -0.025 & -0.003 & $0.25^{* * *}$ & $0.089 * * *$ \\
\hline \multicolumn{5}{|l|}{ Residence } \\
\hline Urban & Ref & & Ref & \\
\hline Rural & $-0.06^{* * *}$ & $-0.007 * * *$ & $-0.07^{* * *}$ & $-0.026^{* * *}$ \\
\hline \multicolumn{5}{|l|}{ Wealth Index } \\
\hline Poorest & Ref & & Ref & \\
\hline Poorer & $0.03^{* * *}$ & 0.003 & $0.23^{* * *}$ & $0.067^{* * *}$ \\
\hline Middle & $0.004^{* * *}$ & 0.0004 & $0.5^{* * *}$ & $0.160^{* * *}$ \\
\hline Richer & $0.020^{* * *}$ & 0.002 & $0.70 * * *$ & $0.235^{* * *}$ \\
\hline Richest & $0.028^{* * *}$ & 0.003 & $0.82 * * *$ & $0.285^{* * *}$ \\
\hline \multicolumn{5}{|l|}{$\begin{array}{l}\text { Currently Smoke } \\
\text { Cigarrettes }\end{array}$} \\
\hline No & Ref & & Ref & \\
\hline Yes & $0.05^{*}$ & 0.006 & $-0.10^{* * *}$ & $-0.035^{* * *}$ \\
\hline \multicolumn{5}{|l|}{ Consume alcohol } \\
\hline No & Ref & & & \\
\hline Yes & -0.007 & -0.001 & & \\
\hline \multicolumn{5}{|l|}{ Consume milk } \\
\hline No & Ref & & Ref & \\
\hline Yes & $-0.037^{* *}$ & $-0.005^{* *}$ & -0.013 & -0.005 \\
\hline \multicolumn{5}{|l|}{ Eats fish } \\
\hline No & Ref & & & \\
\hline Yes & -0.069 & -0.008 & & \\
\hline \multicolumn{5}{|l|}{ Takes aerated drinks } \\
\hline No & & & Ref & \\
\hline Yes & & & $0.18^{* * *}$ & $0.062^{* * *}$ \\
\hline \multicolumn{5}{|l|}{ Eats fruits } \\
\hline No & Ref & & Ref & \\
\hline Yes & -0.033 & -0.004 & $-0.10^{* * *}$ & $-0.036^{* * *}$ \\
\hline \multicolumn{5}{|l|}{ Eats friedfood } \\
\hline No & & & Ref & \\
\hline Yes & & & $-0.07^{* * *}$ & $-0.026^{* * *}$ \\
\hline Constant & $-2.24 * * *$ & & $-1.90^{* * *}$ & \\
\hline Log-likelihood & -79535.69 & & & \\
\hline Rho $(\rho)$ & $-0.247^{* * *}$ & & & \\
\hline Likelihood-ratio test & 8.620 & & & \\
\hline Wald $\chi^{2}$ & 13992.07 & & & \\
\hline
\end{tabular}

Ref: Reference category

$* * *$ P-value $<0.01$

$* *$ P-value $<0.05$.

$*$ P-value $<0.1$

the risk of type 2 diabetes, ${ }^{27}$ and milk intake is significantly related to lower body mass index. ${ }^{28}$ Our study also found that regular consumption of fruits reduces the probability of becoming overweight or obese and hypertensive, as found by previous studies. ${ }^{29}$ Evidence from both prospective and interventional epidemiological studies concludes that an increase in the consumption of fruit and vegetables help in stabilizing weight. ${ }^{29}$ Moreover, Appel (2003), found that interventions in the form of increased consumption of fruits, vegetables, and low-fat dairy
Table 4

Seemingly unrelated bivariate probit model with hypertension and overweight or obesity as the outcome morbidity among adults age 15-49, India, 2014-15.

\begin{tabular}{|c|c|c|c|c|}
\hline \multirow{2}{*}{$\begin{array}{l}\text { Background } \\
\text { Characteristics }\end{array}$} & \multicolumn{2}{|l|}{ Hypertension } & \multicolumn{2}{|c|}{ Overweight or Obese } \\
\hline & Coefficients & Mg.effect & Coefficients & Mg.effect \\
\hline Overweight or Obese & $0.47^{* * *}$ & $0.107 * * *$ & & \\
\hline Age & $0.030 * * *$ & $0.007^{* * *}$ & $0.03^{* * *}$ & $0.01 * * *$ \\
\hline \multicolumn{5}{|l|}{ Sex } \\
\hline Male & Ref & & Ref & \\
\hline Female & $-0.183^{* * *}$ & $-0.045^{* * *}$ & $-0.08^{* * *}$ & $-0.027^{* * *}$ \\
\hline \multicolumn{5}{|l|}{ Caste } \\
\hline Schedule Tribe & Ref & & Ref & \\
\hline Schedule Caste & $0.058^{* *}$ & $0.013^{* *}$ & $-0.05^{* * *}$ & $-0.019 * * *$ \\
\hline Other Backward Caste & $0.070 * * *$ & $0.016^{* * *}$ & $-0.06^{* * *}$ & $-0.023^{* * *}$ \\
\hline Others & 0.009 & 0.003 & -0.008 & -0.003 \\
\hline \multicolumn{5}{|l|}{$\begin{array}{l}\text { Current Marital } \\
\text { Status }\end{array}$} \\
\hline Never married & Ref & & Ref & \\
\hline Married & $-0.056 * * *$ & $-0.013^{* * *}$ & $0.34^{* * *}$ & $0.118^{* * *}$ \\
\hline $\begin{array}{l}\text { Widowed/Divorced/ } \\
\text { Seperated }\end{array}$ & -0.021 & -0.005 & $0.17^{* * *}$ & $0.057^{* * *}$ \\
\hline \multicolumn{5}{|l|}{ Level of education } \\
\hline Illiterate & Ref & & Ref & \\
\hline Primary & $-0.084 * * *$ & $-0.020 * * *$ & 0.02 & 0.008 \\
\hline Secondary & $-0.109 * * *$ & $-0.026^{* * *}$ & $0.12^{* * *}$ & $0.044 * * *$ \\
\hline Higher Secondary & $-0.174 * * *$ & $-0.040 * * *$ & $0.25^{* * *}$ & $0.089 * * *$ \\
\hline \multicolumn{5}{|l|}{ Residence } \\
\hline Urban & Ref & & Ref & \\
\hline Rural & 0.009 & 0.002 & $-0.07^{* * *}$ & $-0.026^{* * *}$ \\
\hline \multicolumn{5}{|l|}{ Wealth Index } \\
\hline Poorest & Ref & & Ref & \\
\hline Poorer & -0.017 & -0.004 & $0.23 * * *$ & $0.067 * * *$ \\
\hline Middle & $-0.098^{* * *}$ & $-0.023 * * *$ & $0.5^{* * *}$ & $0.160 * * *$ \\
\hline Richer & $-0.113^{* * *}$ & $-0.026 * * *$ & $0.70^{* * *}$ & $0.235^{* * *}$ \\
\hline Richest & $-0.185^{* * *}$ & $-0.042^{* * *}$ & $0.82^{* * *}$ & $0.285^{* * *}$ \\
\hline \multicolumn{5}{|l|}{$\begin{array}{l}\text { Currently Smoke } \\
\text { Cigarrettes }\end{array}$} \\
\hline No & Ref & & Ref & \\
\hline Yes & $-0.117 * * *$ & $-0.025^{* * *}$ & $-0.10^{* * *}$ & $-0.035^{* * *}$ \\
\hline \multicolumn{5}{|l|}{ Consume alcohol } \\
\hline No & Ref & & & \\
\hline Yes & $0.159 * * *$ & $0.039 * * *$ & & \\
\hline \multicolumn{5}{|l|}{ Consume milk } \\
\hline No & Ref & & Ref & \\
\hline Yes & 0.022 & 0.005 & -0.012 & -0.005 \\
\hline \multicolumn{5}{|l|}{ Eats fish } \\
\hline No & Ref & & & \\
\hline Yes & -0.041 & -0.009 & & \\
\hline \multicolumn{5}{|l|}{ Takes aerated drinks } \\
\hline No & & & Ref & \\
\hline Yes & & & $0.18^{* * *}$ & $0.062^{* * *}$ \\
\hline \multicolumn{5}{|l|}{ Eats fruits } \\
\hline No & Ref & & Ref & \\
\hline Yes & $-0.068^{*}$ & $-0.016^{*}$ & $-0.10^{* * *}$ & $-0.036^{* * *}$ \\
\hline \multicolumn{5}{|l|}{ Eats friedfood } \\
\hline No & & & Ref & \\
\hline Yes & & & $-0.09^{* * *}$ & $-0.026^{* * *}$ \\
\hline Constant & $-1.84 * * *$ & & $-1.88^{* * *}$ & \\
\hline Log-likelihood & -97992.46 & & & \\
\hline Rho $(\rho)$ & $-0.369 * * *$ & & & \\
\hline Likelihood-ratio test & 46.75 & & & \\
\hline Wald $\chi^{2}$ & 20990.18 & & & \\
\hline
\end{tabular}

Ref: Reference category.

$* * *$ P-value $<0.01$

$* * \mathrm{P}$-value $<0.05$.

*P-value $<0.1$.

products had greater effect in decreasing blood pressure levels in adults with hypertension than interventions for reducing weight, enhanced physical activity, and controlling sodium intake. ${ }^{30}$ The indigenous people of Northeast India are habituated to consuming a wide variety of wild edible fruits and local vegetables which are cheap and easily available. ${ }^{31,32}$ The presence of antioxidants such as phytochemicals in these fruits is of crucial nutritional importance for the prevention of chronic diseases, such as diabetes, cancer and cardiovascular 
Table 5

Elasticity effect of overweight or obesity on the marginal and conditionl probability of having chronic diseases among adults age 15-49, India, 2014-15.

\begin{tabular}{ll}
\hline Probability of chronic disease & Elasticity \\
\hline Prob (Diabetes) & $0.407(4.66)^{* * *}$ \\
Prob (Hypertension) & $0.495(12.80)^{* * *}$ \\
Prob (Diabetes|Overweight or Obese) & $0.473(3.61)^{* * *}$ \\
Prob (Hypertension|Overweight or Obese) & $0.650(7.89)^{* * *}$ \\
\hline
\end{tabular}

$* * * \mathrm{P}$ value $<0.01, \mathrm{Z}$-value in parenthesis. Elasticities are calculates using the marginal effects on the probability the discrete outcome and are evaluated at the mean value.

disease. ${ }^{32,33}$ The protective role of phytochemicals could be related to their antioxidant action. It is known that overproduction of oxidants in the human body is associated with the pathogenesis of many chronic diseases $^{34}$ and thus crucial importance of antioxidants to counter the effects of the oxidants. Several studies have shown the association between consumption of fried foods and the risk of becoming overweight or obese, diabetic and hypertensive. ${ }^{35,36}$ However, the findings of the present study show contrasting results which are supported by other studies. ${ }^{37}$ The inconsistency in the results may be attributed to the type of oils used for frying, and the frying condition-deep or pan fry. ${ }^{35}$

The study has some limitations. For instance, because of the quantitative nature of the study, the unmeasurable information could not be captured, despite being possible to identify their presence. Secondly, an individual is classified as diabetic based on random blood glucose levels which may not be an accurate indicator as compared to fasting blood glucose levels and the 2-h postprandial test. Thirdly, information on the quantity of food consumed by an individual is not available. Lastly, due to the nature of the cross-sectional design of the study, the cause and effect cannot be investigated in detail.

\section{Conclusions}

Our findings provide strong evidence of the role of overweight or obesity as a cause of diabetes and hypertension and also clearly indicates that there are unobserved factors that simultaneously affect overweight/ obesity as well as both diabetes and hypertension. This indicates that apart from the known measurable factors, policy and health promotion programme should also give special attention to the unmeasurable factors (for example: genetic factors, psychological stress and long working hour) that commonly influence the risk of overweight or obesity and chronic diseases.

\section{Acknowledgement}

None.

\section{Funding}

This research did not receive any specific grant from funding agencies in the public, commercial, or not-for-profit sectors.

\section{Ethical statement}

NFHS data is publicly available, respondents de-identified and the institutional review board (IRB) of IIPS, Mumbai exempted from requiring IRB approval.

\section{Data source}

https://dhsprogram.com/data/dataset/India_Standard-DHS_2015. cfm? flag $=1$.

\section{Declaration of competing interest}

No potential conflict of interest relevant to this article was reported.

\section{Appendix A. Supplementary data}

Supplementary data to this article can be found online at https://doi. org/10.1016/j.cegh.2021.100764.

\section{References}

1 International Institute for Population Sciences (IIPS) and Macro International. National Family Health Survey (NFHS-3), 2005-06: India. vol. I. Mumbai: IIPS; 2007. Available from http://rchiips.org/nfhs/NFHS-3 Data/VOL-1/India_volume_I_co rrected 17oct08.pdf.

2 Mungreiphy NK, Kapoor S, Sinha R. Association between BMI, blood pressure, and age: study among tangkhul naga tribal males of Northeast India. J Anthropol. 2011; 2011:1-6. Available from https://www.hindawi.com/archive/2011/748147/.

3 Mandal A. Study of prevalence of type 2 diabetes mellitus and hypertension in overweight and obese people. J Fam Med Prim Care. 2014;3(1):25-28. Available from, https://dx.doi.org/10.4103/2249-4863.130265.

4 Costa-Font J, Gil J. Obesity and the incidence of chronic diseases in Spain: a seemingly unrelated probit approach. Econ Hum Biol. 2005 Jul;3(2):188-214. Available from https://linkinghub.elsevier.com/retrieve/pii/S1570677X05000316.

5 Herrera BM, Lindgren CM. The genetics of obesity. Curr Diabetes Rep. 2010 Dec 8;10 (6):498-505. Available from http://link.springer.com/10.1007/s11892-010-0153-z.

6 Gupta S, Bansal S. Does a rise in BMI cause an increased risk of diabetes?: evidence from India. PloS One. 2020;15(4):1-20. https://doi.org/10.1371/journal. pone. 0229716. Available from.

7 Yamada Y, Ishizaki M, Tsuritani I. Prevention of weight gain and obesity in occupational populations: a new target of health promotion services at worksites. J Occup Health. 2002 Nov 28;44(6):373-384. Available from https://onlinelibrary. wiley.com/doi/abs/10.1539/joh.44.373.

8 Roberts MR, Whited TM. Endogeneity in empirical corporate Finance1. In: Constantinides, et al., eds. Handbook of the Economics of Finance. first ed. Elsevier BV; 2013:493-572. Available from https://linkinghub.elsevier.com/retrieve/pii/B 9780444535948000070.

9 Abdallah W, Goergen M, O'Sullivan N. Endogeneity: how failure to correct for it can cause wrong inferences and some remedies. Br J Manag. 2015 Oct;26(4):791-804. Available from, http://doi.org/10.1111/1467-8551.12113.

10 Reis AM, Quintal C, Ó Lourenço. Killing two birds with one stone? Association between tobacco and alcohol consumption. Publ Health. 2018 Jan;154:136-143. Available from, https://www.sciencedirect.com/science/article/abs/pii/S00333 50617303542?via\%3Dihub.

11 International Institute for Population Sciences (IIPS) and ICF. National Family Health Survey (NFHS-4), 2015-16: India. Mumbai: IIPS; 2017. Available from http://rchiips. org/nfhs/NFHS-4Reports/India.pdf.

12 Barba C, Cavalli-Sforza T, Cutter J, et al. Appropriate body-mass index for Asian populations and its implications for policy and intervention strategies. Lancet. 2004 Jan;363(9403):157-163. Available from https://linkinghub.elsevier.com/retrieve /pii/S0140673603152683.

13 Seyoum S. Analysis of prevalence of malaria and anemia using bivariate probit model. Ann Data Sci. 2018 Jun 19;5(2):301-312. https://doi.org/10.1007/s40745 018-0138-3. Available from.

14 Fabbri D, Monfardini C, Radice R. Testing Exogeneity in the Bivariate Probit Model: Monte Carlo Evidence and an Application to Health Economics. Work Pap; 2004.

15 Dixit P, Khan J, Dwivedi LK, Gupta A. Dimensions of antenatal care service and the alacrity of mothers towards institutional delivery in South and South East Asia. PloS One. 2017;12(7):1-16.

16 Siddiqui S. Obesity and diabetes: interrelationship. Adv Obesity. Weight Manag Control. 2018 Apr 26;8(2):155-158. Available from https://medcraveonline.com/ AOWMC/obesity-and-diabetes-interrelationship.html.

17 Anto EO, Owiredu WKBA, Adua E, et al. Prevalence and lifestyle-related risk factors of obesity and unrecognized hypertension among bus drivers in Ghana. Heliyon. 2020;6(1), e03147. https://doi.org/10.1016/j.heliyon.2019.e03147. Available from.

18 Luhar S, Mallinson PAC, Clarke L, Kinra S. Trends in the socioeconomic patterning of overweight/obesity in India: a repeated cross-sectional study using nationally representative data. BMJ Open. 2018;8(10):6-9.

19 Gouda J, Prusty RK. Overweight and obesity among women by economic stratum in Urban India. J Health Popul Nutr. 2014;32(1):79-88.

20 Umberson D. Gender, marital status and the social control of health behavior. Soc Sci Med. 1992;34(8):907-917.

21 Lipowicz A, Gronkiewicz S, Malina RM. Body mass index, overweight and obesity in married and never married men and women in Poland. Am J Hum Biol. 2002;14(4): 468-475.

22 Sobal J, Rauschenbach BS, Frongillo EA. Marital status, fatness and obesity. Soc Sci Med. 1992 Oct;35(7):915-923. Available from https://linkinghub.elsevier.com/ret rieve/pii/027795369290106Z.

23 Rauschenbach B, Sobal J, Frongillo EA. The influence of change in marital status on weight change over one year. Obes Res. 1995;3(4):319-327.

24 McNagny SE, Ahluwalia JS, Clark WS, Resnicow KA. Cigarette smoking and severe uncontrolled hypertension in inner-city african Americans. Am J Med. 1997 Aug;103 
(2):121-127. Available from https://linkinghub.elsevier.com/retrieve/pii S0002934398001053.

25 Liu X, Byrd JB. Cigarette smoking and subtypes of uncontrolled blood pressure among diagnosed hypertensive patients: paradoxical associations and implications. Am J Hypertens. 2017 Jun 1;30(6):602-609. Available from https://academic.oup. $\mathrm{com} / \mathrm{ajh} / \mathrm{article-lookup/doi/10.1093/ajh/hpx014.}$

26 Freitas SRS, Alvim RO. Smoking and blood pressure phenotypes: new perspective for an old problem. Am J Hypertens. 2017;30(6):554-555.

27 Pasin G, Comerford KB. Dairy foods and dairy proteins in the management of type 2 diabetes: a systematic review of the clinical evidence. Adv Nutr. 2015;6(3):245-259.

28 Marques-Vidal P, Gonçalves A, Dias CM. Milk intake is inversely related to obesity in men and in young women: data from the Portuguese Health Interview Survey 1998-1999. Int J Obes. 2006 Jan 23;30(1):88-93. Available from http://www.nature .com/articles/0803045.

29 Boeing H, Bechthold A, Bub A, et al. Critical review: vegetables and fruit in the prevention of chronic diseases. Eur J Nutr. 2012;51(6):637-663.

30 Appel LJ. Effects of comprehensive lifestyle modification on blood pressure control. J Am Med Assoc. 2003 Apr 23;289(16):2083-2093. Available from http://jama. jamanetwork.com/article.aspx?doi=10.1001/jama.289.16.2083.

31 Kumar V, Angami T, Ansari MT, Ramjan M. Health promoting phytochemicals of minor vegetables from North east India. Int J Adv Biol Res. 2019;9(3):186-192.
32 Pachuau L, Dutta RS. Wild edible fruits of Northeast India: medicinal values and traditional practices. In: Sen, et al., eds. Herbal Medicine in India. Springer Singapore; 2020:437-450. Available from http://link.springer.com/10.1007/978-981-13-7248327.

33 Chu Y-F, Sun J, Wu X, Liu RH. Antioxidant and antiproliferative activities of common vegetables. J Agric Food Chem. 2002 Nov;50(23):6910-6916. Available from https:// pubs.acs.org/doi/10.1021/jf020665f.

34 Zhang YJ, Gan RY, Li S, et al. Antioxidant phytochemicals for the prevention and treatment of chronic diseases. Molecules. 2015;20(12):21138-21156.

35 Gadiraju TV, Patel Y, Gaziano JM, Djoussé L. Fried food consumption and cardiovascular health: a review of current evidence. Nutrients. 2015;7(10): 8424-8430.

36 Honerlaw JP, Ho YL, Nguyen XMT, et al. Fried food consumption and risk of coronary artery disease: the Million Veteran Program. Clin Nutr. 2020;39(4): 1203-1208.

37 Cahill LE, Pan A, Chiuve SE, et al. Fried-food consumption and risk of type 2 diabetes and coronary artery disease: a prospective study in 2 cohorts of US women and men. Am J Clin Nutr. 2014 Aug 1;100(2):667-675. Available from https://academic.oup. com/ajcn/article/100/2/667/4576562. 